INEEL/CON-99-01115
PREPRINT

Estimating Production Potentials: Expert Bias in Applied Decision Making

\author{
Wendy J. Reece (INEEL) \\ Leroy J. Matthews (ISU) \\ Linda K. Burggraff (ISU)
}

October 28, 1998 - October 30, 1998

\section{Engineering Psychology \& Cognitive Ergonomics}

This is a preprint of a paper intended for publication in a journal or proceedings. Since changes may be made before publication, this preprint should not be cited or reproduced without permission of the author.

This document was prepared as a account of work sponsored by an agency of the United States Government. Neither the United States Government nor any agency thereof, or any of their employees, makes any warranty, expressed or implied, or assumes any legal liability or responsibility for any third party's use, or the results of such use, of any information, apparatus, product or process disclosed in this report, or represents that its use by such third party would not infringe privately owned rights. The views expressed in this paper are not necessarily those of the U.S. Government or the sponsoring agency. 


\title{
Estimating production potentials: \\ Expert bias in applied decision making
}

Leroy J. Matthews

Idaho State University

Wendy J. Reece

Idaho National Engineering \& Environmental Laboratory

Linda K. Burggraf

Idaho State University

\begin{abstract}
A study was conducted to evaluate how workers predict manufacturing production potentials given positively and negatively framed information. Findings indicate the existence of a bias toward positive information and suggest that this bias may be reduced with experience but is never the less maintained. Experts err in the same way non experts do in differentially processing negative and positive information. Additionally, both experts and non experts tend to overestimate production potentials in a positive direction. The authors propose that these biases should be addressed with further research including cross domain analyses and consideration in training, workplace design, and human performance modeling.
\end{abstract}




\section{Background}

Early cognitive theory proposed a mathematical notion of decision makers as 'intuitive statisticians' (Peterson and Beach, 1967) in judging probabilities. Further research indicated that, among other things, decision makers tend to be more conservative in predictions than a statistical model would indicate (Edwards, 1968) and that human decisions are a function of heuristics and biases (Tversky and Kahneman, 1974). Taylor and Brown (1988) propose that cognitive processing mechanisms impose filters on incoming information, distorting it in a positive direction and isolating negative information. This serves as a basis for errors of inference in decision making due to the inaccuracy of selective processing and a bias toward positively framed information. As noted by Kuhlberger (1995) the way in which problems are presented may help reduce or eliminate framing effects and associated biases.

It has been noted that experts and non experts may experience the same biases in decision making (Ericsson and Staszewski, 1989). The extent to which the positive bias is retained or disappears in expert decision making has not been explored in prior applied research.

\section{Method}

A study was conducted to investigate how levels of expertise and the framing of information affect predictions in an industrial workplace. Facility operations management was interested in learning how employees integrate and utilize positive and negative information about production potentials.

Thirty-two subjects were randomly selected from a total population of 400 employees working in various job positions at a manufacturing facility. Years of industry experience and formal education were noted for each subject. The median number of years of experience and the median level of formal education were calculated for the group, and two levels of expertise were identified. Experts were defined as those subjects with greater than the median level of experience and education, and non experts were those with less than the median level of experience or education.

Subjects were asked to predict future production percentages based on sample production rates from two preceding months. Production evidence was presented in two formats: yield percentage rates, or the quantity of remaining useable materials from which quality products can be 
manufactured; and scrap percentage rates, or the portion of remaining unusable materials. High yield and low scrap rates are considered favorable, positive production conditions, while low yield and high scrap are less favorable, negative conditions in the manufacturing industry.

Company officials affirmed that the sample yield and scrap rates used in this study were representative of facility production levels. Inconsistent sets of information were incorporated in the prediction task to further provide ecological validity, as real world decisions are rarely based on consistent evidence. The order of presentation of tasks was randomized and the presented evidence was counterbalanced to control for order effects.

\section{Results and discussion}

Analyses of results examined differences between experts' and non experts' predictions given yield or scrap evidence. The unit of analysis for descriptive and quantitative computations was the algebraic difference between the mean of the presented evidence and the subjects' prediction of a future percentage.

Figure 1 and Figure 2 display the mean predictions of experts' and non experts' for future production levels, based on scrap and yield evidence respectively. In each graph, horizontal and diagonal reference lines are provided to help discriminate subjects' performance. As illustrated in the figures, non experts displayed less symmetry in responding to negative and positive evidence $(\mathrm{p}<.05)$. They tended to predict future levels much closer to the presented evidence when the evidence was of a positive nature than when it was negative. In contrast, experts' predictions were significantly $(p<.05)$ closer to the presented evidence across all levels of previous production output. However, both groups responded differently to the positive and negative evidence $(\mathrm{p}<.01)$, although this result was less pronounced among experts.

Results indicated that both experts and non experts predicted more favorable, positive production outcomes than would be calculated arithmetically. As noted in Table 1, subjects provided predictions that were more positive than the evidence warranted for both scrap- and yield-based sample production rates $(\mathrm{p}<.01)$. Table 2 shows the percentage of subjects who overestimated production outcomes. Overall, the majority of subjects in this study responded to both the yield and scrap evidence with excessively positive predictions. An interpretation of this finding is that both groups of subjects placed too little importance upon negative evidence, resulting in 


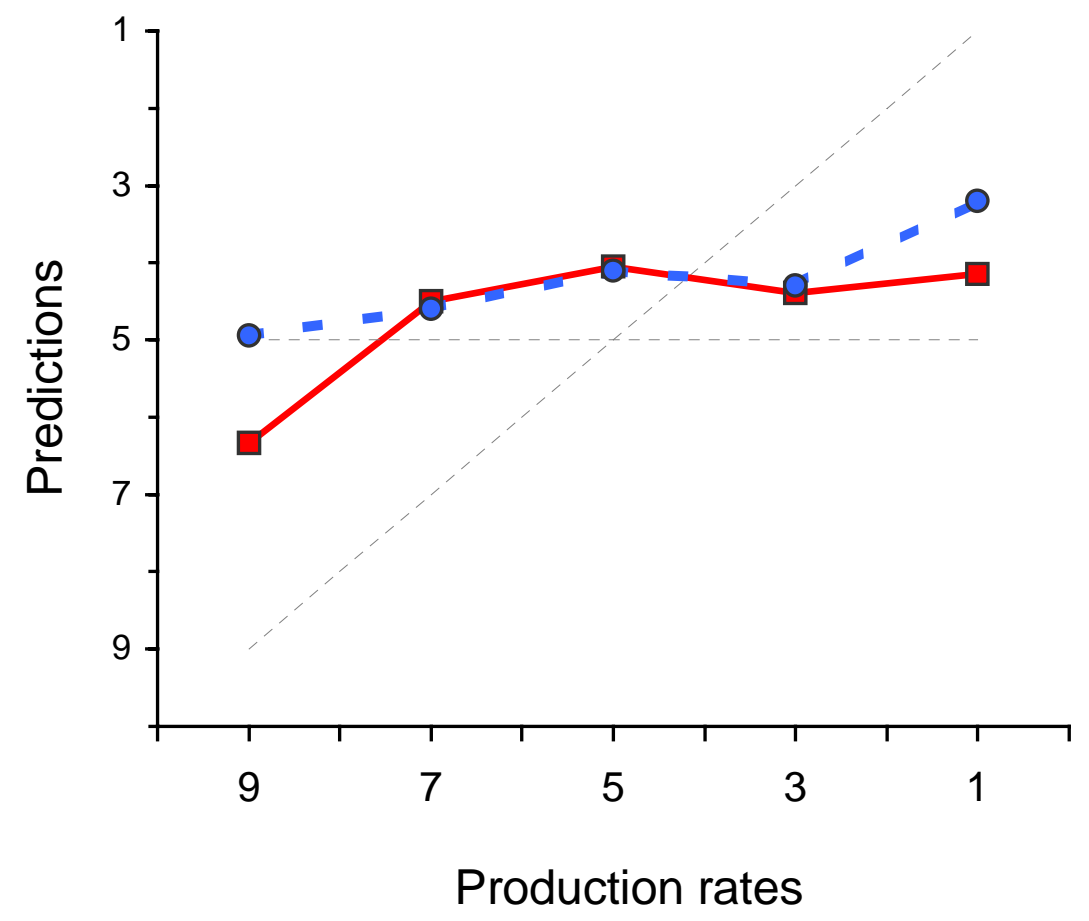

\section{Figure 1 Predictions based on Scrap}

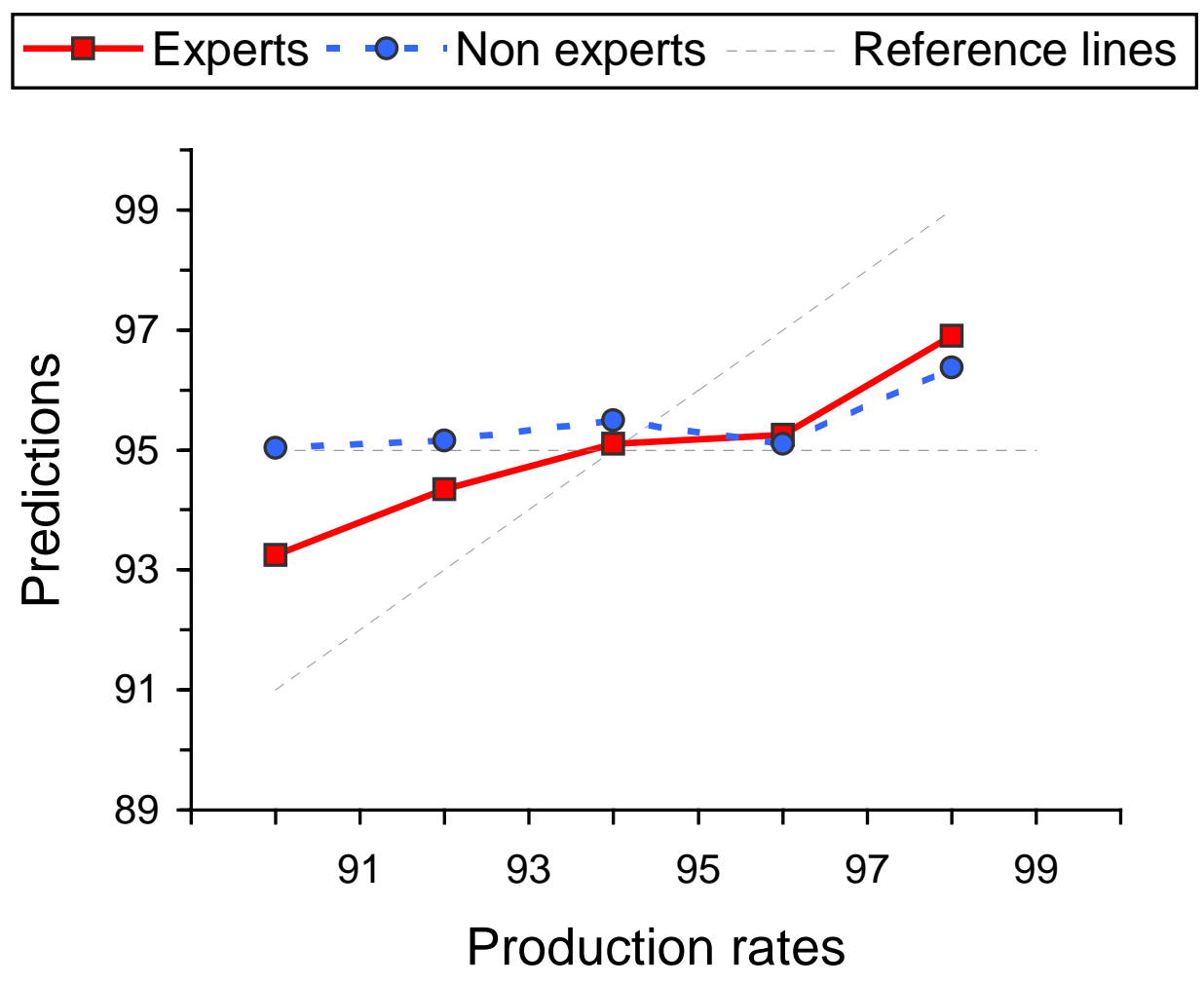

Figure 2 Predictions based on Yield 


\section{Table 1}

\section{Predicted production levels}

$\begin{array}{lccr} & \begin{array}{c}\text { Predictions based } \\ \text { on Scrap evidence } \\ (\text { mean = 5) }\end{array} & \begin{array}{c}\text { Predictions based } \\ \text { on Yield evidence } \\ (\text { mean = 95) }\end{array} & \text { Difference } \\ \text { Experts } & 4.75 & 95.27 & +.24 \\ \text { Non Experts } & 4.43 & 95.15 & +.36 \\ & & & \\ \text { Difference } & +.41 & +.21 & \end{array}$

\section{Table 2}

Percentage of overly positive predictions

Predictions based Predictions based on Scrap evidence on Yield evidence Total

Expert

$60 \%$

$70 \%$

$65 \%$

Overestimates

Non Expert

$73 \%$

$82 \%$

$77 \%$

Overestimates

Total

$76 \%$

$67 \%$ 
overestimation of future manufacturing outcomes. It should be noted, however, that a greater percentage of subjects in the non expert group provided overly positive production predictions. This supports the notion that expertise may reduce the positive bias in information processing.

The data indicate more difficulty in processing negative information than positive information in both yield and scrap tasks. Higher levels of expertise were associated with closer approximations to a statistical assessment of production performance, but subjects in both groups displayed at least some overestimation of future outcomes. These findings suggest that even experts fail to integrate positive and negative evidence equally. Work experience and education may moderate the tendency to under utilize negative information, but it does not eliminate this bias.

Previous research has shown that experts tend to be more coherent in their representation of tasks (Gaeth and Shanteau, 1984). According to this finding, experts should have displayed less variability in their responses across scrap and yield scenarios in the present study. However, experts showed less variability when responding to evidence expressed as yield but not in scenarios with scrap evidence $(\mathrm{p}<.05)$. A possible explanation for this may be that decision makers, regardless of expertise, find it easier to integrate evidence when it has a positive meaning (e.g., amount of yield) rather than a negative meaning (e.g., amount of scrap). This interpretation is consistent with the general conclusion of other studies regarding the facilitative role of positive evidence on human information processing (Matlin and Stang, 1978; Taylor and Brown, 1988; Reece and Matthews, 1993).

Differences in processing between levels of expertise and differential processing of negative and positive information for both experts and non experts were confirmed with the results of this study. These findings are in line with other documented research (Tversky and Kahneman, 1981) suggesting that decision makers may process and utilize information differently depending on the framing of the problem.

\section{Conclusions}

Our findings indicate that the bias toward positively framed information does exist. Expertise may improve processing and integration of negative information and reduce this bias. However, even experts tend to process negative and positive information differently. Additionally, this study 
substantiated the theory that decision makers tend to predict more favorable outcomes than evidence would dictate.

To transfer these research findings to workplace applications, several methods are proposed. Operations management could utilize this information about judgment biases in workplace training. The intent would be to help decision makers improve accuracy in prediction through awareness of possible biases, and training workers to consider all aspects of presented information before making judgments.

If information is more readily attended to when framed in a positive manner, display designs and information presentation formats should be oriented accordingly. For example, in the manufacturing industry, status displays providing yield data would facilitate more accurate and complete information processing in predictions of plant production levels.

Another application for the results of this study is in the analysis of worker performance. Human reliability models account for many factors, including the cognitive components of worker behavior. It is suggested that the bias toward positive, favorable information should be considered as a potential performance shaping factor in assessments of predictive judgment tasks.

Further research is needed to assess whether the phenomena noted in this study similarly impact predictive decision making performance in other domain applications. In conclusion, differential processing of negative and positive information should be considered as a cognitive component of error producing contexts in applied decision making, and accommodated for in training, system design and performance reliability analyses.

\section{References}

Andriole, S. and Adelman, L. (1995). Cognitive Systems Engineering for User-Computer Interface Design, Prototyping, and Evaluation. Hove, UK: Lawrence Erlbaum Associates.

Edwards, W. (1968). 'Conservatism in human information processing', in

B. Kleinmuntz (ed.), Formal Representation of Human Judgment. (pp.1752). New York: John Wiley.

Ericsson, K. A., and Staszewski, J. J. (1989). 'Skilled Memory and Expertise: Mechanisms of Exceptional Performance', in Klahr, D. and Kotovsky, K. (eds.), Complex Information Processing (pp.235-267). Hove, UK: Lawrence Erlbaum Associates. 
Gaeth, R., and Shanteau, J. (1984). 'Reducing the influence of irrelevant information on experienced decision makers. Organizational Behavior and Human Performance, 33, pp.263-282.

Kuhlberger, A. (1995). 'The framing of decisions: A new look at old problems'. Organizational Behavior and Human Decision Processes, 62, pp.230-240.

Lehto, M. (1997). 'Decision making', in Salvendy, G. (ed.), Handbook of Human Factors and Ergonomics, Second Edition, (pp.1201-1248). New York: John Wiley \& Sons, Inc.

Matlin, M. W., and Stang, D. J. (1978). The Pollyanna Principle. Cambridge: Schenkman Publishing Co.

Tversky, A., and Kahneman, D. (1974). 'Judgment under uncertainty: Heuristics and biases'. Science, 185, pp.1124-1131.

Tversky, A., and Kahneman, D. (1981). 'The framing of decisions and the psychology of choice'. Science, 211, pp.453-458.

Taylor, S. E., and Brown, J. D. (1988). 'Illusion and well-being: A social psychological perspective on mental health'. Psychological Bulletin, 103, 2, pp.193-210.

Reece, W. J., and Matthews, L. J. (1993). 'Evidence and uncertainty in subjective prediction: Influences on optimistic judgment'. Psychological Reports, 72, pp.435-439.

Peterson, C. R., and Beach, L. R. (1967). 'Man as an intuitive statistician'. Psychological Bulletin, 68, 1, pp.29-46. 